\title{
Access Control with Automated on Duty Notification Tool in air traffic Services
}

\author{
Nkululeko Ntombela \\ Air Traffic and Navigation Services \\ Johannesburg, South Africa \\ nkululekon@atns.co.za
}

\author{
Patrice Umenne \\ Department of Electrical and Mining Engineering \\ University of South Africa \\ Johannesburg, South Africa \\ umennpo@unisa.ac.za
}

\begin{abstract}
This project provides a solution that alerts management if an Air Traffic Service Unit (ATSU) tower is unmanned during operational hours. The project makes provision for an access control with an automated on duty notification tool. The Air traffic controller activates a report for the on-duty system real time when he accesses the tower. The control system is used to send notification to the line management if the air traffic control tower is unmanned at any time. Escalation to the next level management occurs automatically every 15 minutes if the tower is unmanned until it reaches the senior management of the air traffic services. The project is modelled in Proteus software. The proteus software is interfaced to a Global System for Mobile Communications (GSM) module for communication as an automated notification tool.
\end{abstract}

Keywords - Air traffic service Unit (ATSU), Air traffic controller (ATC), Air Traffic and Navigation Services (ATNS), Air traffic Services Resource Tool (ATSR), Proteus.

\section{INTRODUCTION}

The objective of this paper is to discuss an access control with automated on duty notification tool. This project will assist Air Traffic and Navigation Services (ATNS) to address the problem of management not getting notification if the Air Traffic Service Unit (ATSU) tower [1] is unmanned during operation hours. The importance of the air Traffic Service Unit (ATSU) is that it gives the flight crew and the aircraft systems in the tower a way of managing the communication between the aircraft and air Traffic Service (ATS) centers. This makes the ATSU a very important component of air traffic control. The availability of air traffic controllers (ATC) at towers during centre operating times is of crucial importance. There are situations where air traffic controllers are not available to attend to communications in the air traffic tower. This needs to be resolved by using automatic notification systems as in [2-3] tool to inform the management that the tower is unmanned and create a record in the database. In the ever-changing world of technology and innovation, there are opportunities for ATNS to develop. The notification tool will assist in monitoring the availability of air traffic controllers at the towers as required. In analyzing the current environment, it has been noted that ATNS currently utilizes Air Traffic Services Resource Tool (ATSR), which would record the presence or absence of a controller but would not notify management, hence the improvement to the system will assist to create the added function of communicating the status to the management. Air Traffic Flow management (ATFM) is discussed in [4]. As air transport demand grows more quickly there is a need to have effective management of air traffic. The article reviews current research on air traffic flow management (ATFM) that is based on modelling. The air traffic flow can be used as information by air traffic controllers (ATC) to avoid any accidents or catastrophes.

Air traffic control is gradually being improved in air travel. The paper in [5] discusses an air traffic control system called High Desert Tracon. This is a radar approach based control facility and advanced automation system. The paper also discusses a Center-Tracon Automation system.

As the volume of flights increases air traffic controllers will rely more on automated tools [6] to be able to perform their tasks. New automation tools will need to be invented constantly. The paper in [6] focuses on system engineering specializations that will deal with the impact of relying on automation. From a human perspective when dealing with a system of systems on automation, there will be attention span errors, automation errors and effects on safety. Therefore, automation algorithms would need to be improved to assist the human air traffic controllers. Software for the development of algorithms would need to be improved and the multi-core processors for hosting these algorithms would also need to be improved.

The airspace system's safety is dependent on air traffic control (ATC). With progress in satellite navigation and automation systems, some people suggest increasing the level of automation in ATC to meet safety standards [7]. However, another problem arises as a result of this which is that if you keep increasing the level of automation at some point the controller's margin of being able to perform their tasks will reduce. Therefore, human factor in ATC starts to play a role. As a result, in air transport, research panels that deal with human factors in air traffic control are now being formed to address these issues. 
Concern has been shown that automation of air traffic control could lead to a negative impact on the cognitive functioning of the brain and as a result affect performance. This was investigated empirically in [8] by comparing conventional air traffic control and a simulation designed to be analogous to extreme automation. The result was that the cognitive functions of the brain such as visual search and flight recalls were not affected by the simulation analogous to extreme automation. Actually, cognitive brain functions such as memory and planning improved. Some explanations towards this result could be that the controller had a reduced workload using automation tools that freed up time for the controller to get information in other ways.

Next Generation has added new automated equipment to assist air traffic controllers (ATCos) manage increase in air traffic. The paper in [9] studies the level of trust metrics that air traffic controllers (ATCos) have for their automation equipment. The paper examines the relationship between the subjective trust measures to the ATCos behaviors. Results show that ATCos who scored high on the trust measures had reduced situation awareness when using the automation equipment and those who scored low on the trust measures had increased situation awareness when using the automation equipment. This could probably be as a result of automation complacency. In order words when the ATCos trust the equipment they could be more relaxed when using it which is not necessarily a good thing.

In [10] the effects of conflict geometry on human factors of Air traffic controllers (ATCos) as it pertains to air travel is studied. The paper studies the effect of conflict geometry on situation awareness and stress level of ATCos. The results indicate that crossing conflicts lead to a reduced situation awareness.

Increasing the level of automation in air traffic is used to increase the performance of service. This leads to new roles for the controller, who will monitor automated systems without intervening much [11]. As a result, the Air traffic controllers (ATCos) would operate in a sort of supervisory role rather in a direct mode. However, in such an operating mode human errors can occur called out of the loop (OOTL) errors. These could include lack of attention and deskilling. To solve this problem a new technology is being introduced called adaptive automation (AA). In this system the controller interfaces to the machine through his senses such as eyes and is able to give operative instructions to the machine based on their needs. As a result, the ATCos mental state can be used as control logic for the machines. In this paper techniques such as eye-tracking can be used to determine the vigilance of the controller when using the machine. The results show that highly automated tasks tend to reduce vigilance of controllers.

\section{METHODOLOGY}

ATNS has historically and continues to be notified either by third party whether there is an Air Traffic Controller (ATC) at the tower. The current systems at the Air Traffic Service units (ATSU) makes it difficult for ATNS management to be aware if the tower is not manned as expected. Unmanned Air Traffic Service Unit creates a situation that is more likely to result in accidents as communication between ATC and Pilot will not be available as expected.
This paper discusses the design of an access control with automated on duty notification tool. This design monitors the entrance at the air traffic service unit (ATSU) tower and if there is no entry made by the Air Traffic Controller (ATC) during opening time, it will notify the management of that unit via SMS and escalate the notification every $15 \mathrm{~min}$ if the status remains the same.

In this paper the following concepts were implemented. Comparing the dialed access code with the security code in the PIC Memory. If there is a match, it grants access by activating the relay that will then enable the door magnet (Door Lock) to be de-activated (opened), the Liquid Crystal Display (LCD) shows message "SUCCESS" and the buzzer sounds once. If the dialed code does not match with the security code, the door lock does not de-activate (open), the LCD shows "ERROR", the buzzer sounds twice, and the counter keeps logs of every entry.

By using the PIC Microcontroller internal timer, at a specific time it interrupts the PIC program and forces it to check if the tower has been opened (Check the number of entries), if there is no entry, it will send a command to the GSM module to Send a notification via SMS to management (for example if the tower is not manned at 6:30am) and escalate this every $15 \mathrm{~min}$ with the SMS as can be seen by the flow chart in Fig.1. The PIC microcontroller can be used for this and other similar applications such as [12-13]. Time of the short message changes if the status stays the same during escalation.
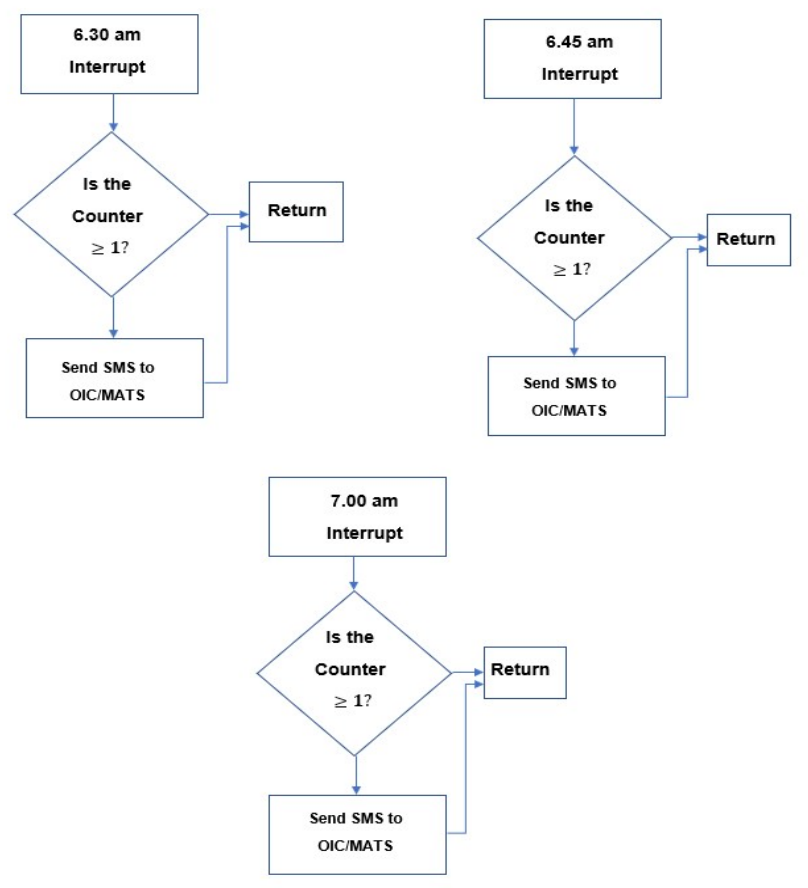

Fig. 1 Interrupt Program Flow Chart

All the ATC's will be allocated individual access code that they will use to access the building by entering the code on the keypad, the entered code is verified by the PIC Microcontroller and the ATC's are granted access if successful by sending a command to a magnetic door lock.

If none of the allocated access codes has been entered during opening time the PIC Microcontroller sends a command to the GSM module to activate a notification SMS that will be sent out 
to the Manager Air Traffic Services (MATS) or escalated to the Senior Manager Air Traffic Services (SMATS) and Chief Air Traffic Services (CATS) CEO.

The project design consists of two units: Slave Unit - Consists of 4x3 Matrix Keyboard, 2x16 LCD, Transceiver MCP2021500, PIC18F46K80 Microcontroller, magnetic buzzer located at the door this is summarized in the block diagram in Fig.2.

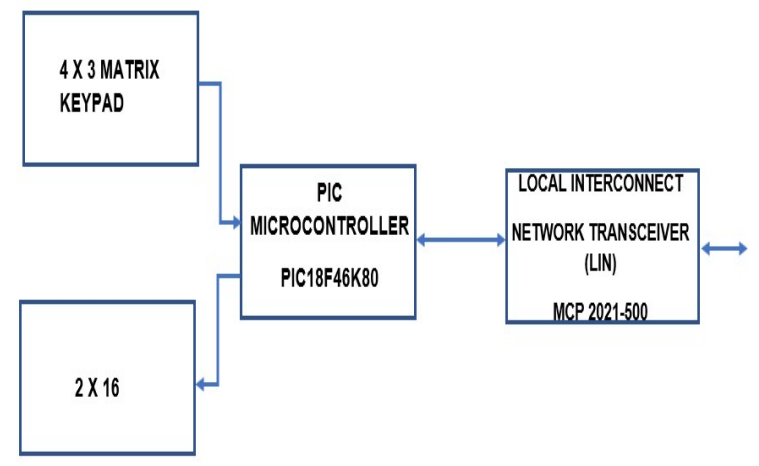

Fig. 2 Slave Unit Block Diagram

Master Unit - Consists of transceiver MCP2021-500, PIC18F46K80 Microcontroller, GSM Modem SIM5300, Omron SPDT Non-Latching Relay PCB Mount, 5V DC Coil, that energizes the magnetic lock and Power Supply unit $12 \mathrm{~V} \&$ 4.5 V placed inside the building as can be seen in Fig. 3.

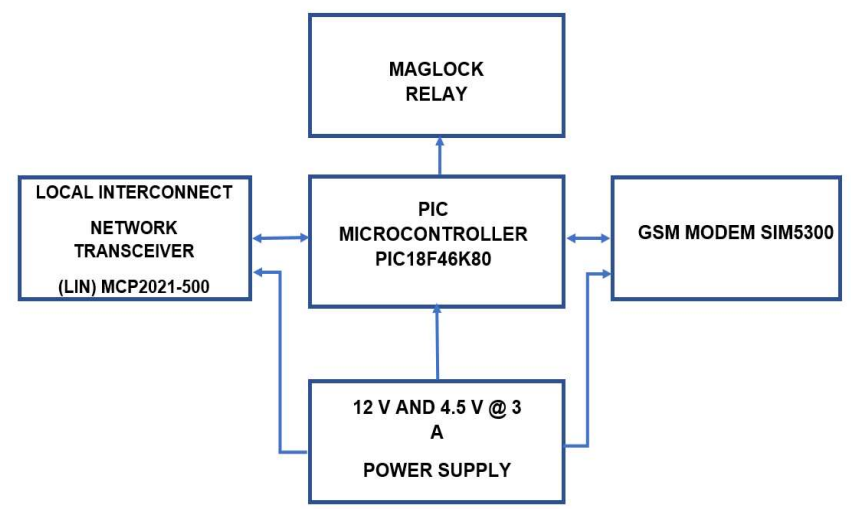

Fig. 3 Master Unit Block Diagram

\section{A. Simulated Design}

The project was summarized and then simulated in proteus software [14-15] as can be seen in Fig. 4 to consist of the following components:

Slave Unit; 4x3 Matrix Keyboard, 2x16 LCD, Transceiver MCP2021-500, PIC18F46K80 Microcontroller, Red LED (Buzzer) and Blue LED (Magnetic Door Relay).

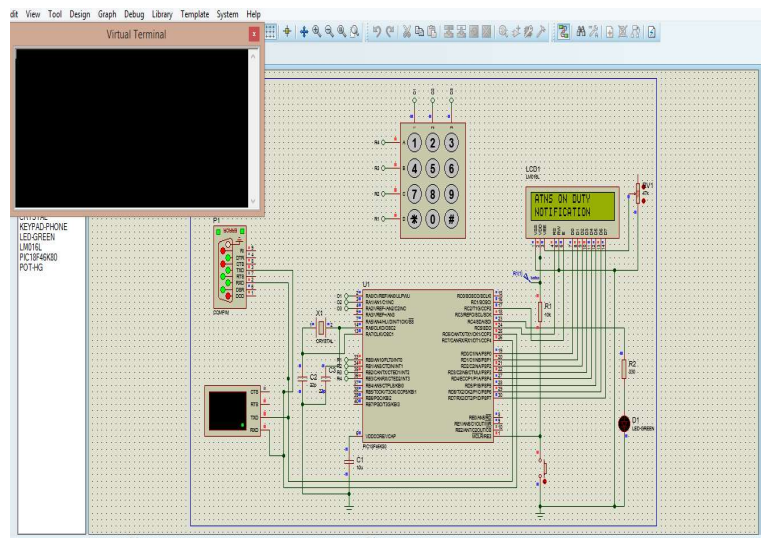

Fig. 4 Simulated Project Design

The block diagram summarizing the design can be seen in Fig 5 below.

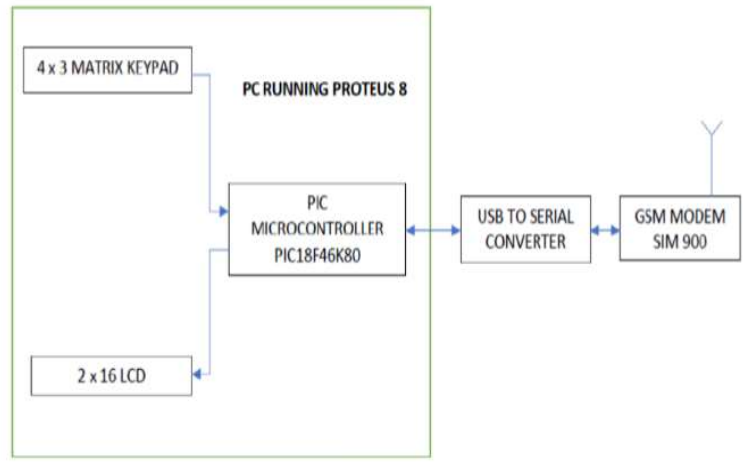

Fig. 5 Simulated Project Block Design

The 4 X 3 MATRIX KEPAD, 2 X 16 LCD and PIC18F46K80 used are simulated within Proteus Software Library. The PIC Microcontroller Assembly Code is added as a firmware within Proteus 8 . The proteus assembly is connected to a USB to serial converter and then to a GSM module to communicate with a database and line management.

\section{TESTING OF THE SIMULATED MODEL AND RESULTS ANALYSIS.}

The virtual ports in the Proteus Software offer an option to connect the external hardware to the simulation software. In this test procedure we utilized this option by connecting a GSM module via a USB to serial converter to communicate with the Proteus Software simulated circuit. The GSM module is interfaced with the virtual ports in Proteus. The GSM module communicates with the microcontroller inside the simulation software. This eliminates the requirement of hardware components for testing the circuit idea. The only hardware components used were the GSM Module and the USB Serial converter.

Before the complete circuit can be simulated the following tests are performed: Test Virtual COM Ports in Proteus to interface with USB serial converter. Connecting USB to serial converter with GSM Module. Test communication between Proteus Virtual COM Ports and the GSM module using AT commands (Attention commands). Communication results analysis. 
The parameters of the virtual terminal are set to match with the external GSM module at a baud rate of 9600 bps.

For the USB to Serial converter used, the output of this converter is 5 Volts or 3.3Volts TTL Logic. This output is connected to the GSM Module directly as shown in Fig. 6. The USB Serial Converter Tx terminal is connected to GSM Module $\mathrm{Rx}$, USB Serial Converter Rx connected to GSM Module Tx and Grounds connected.

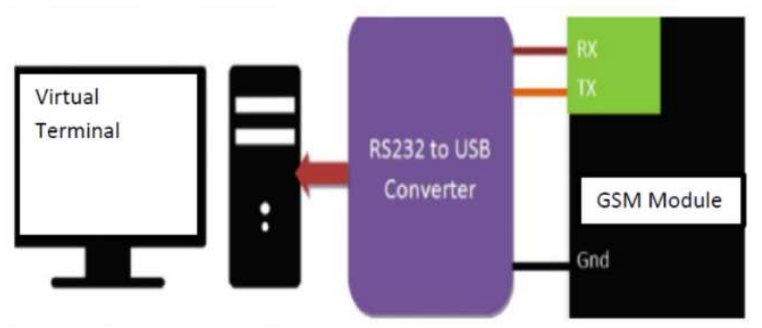

Fig. 6 Virtual \& Physical Communication diagram - Tested

The USB to serial converter and the GSM module can be seen in Fig. 7 and 8 below.

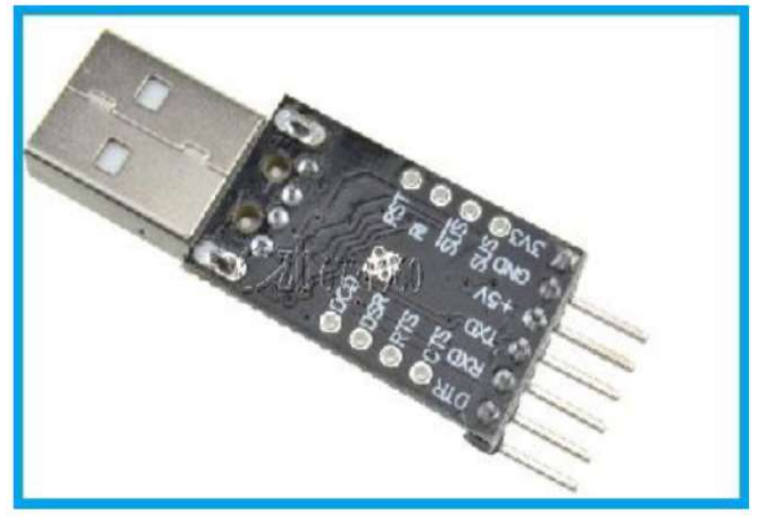

Fig. 7 USB to Serial converter

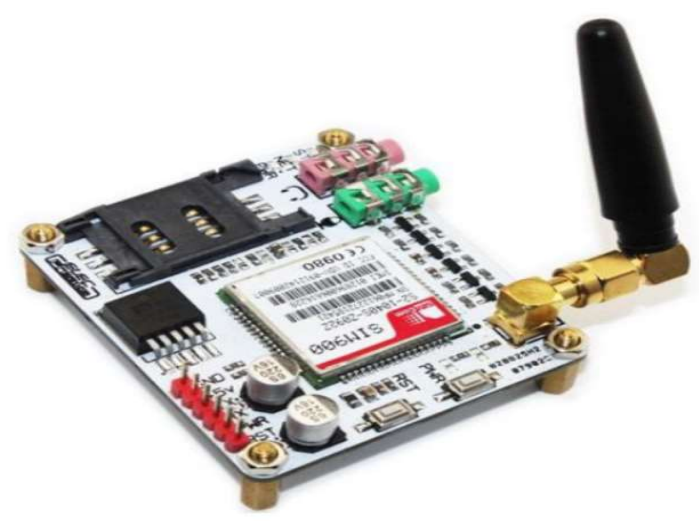

Fig. 8 GSM Module and Antenna

Finally, test the communication between the PC housing the proteus model and the GSM module to make sure the two are communicating. The communication between the two can be determined to be in order by using AT Commands (Attention commands) as is done in [16]. When you enter the "AT" commands as in [17], you receive a confirmation "OK" to indicate that communication has been established.
The Communication baud rate is set to:

GSM Modem 9600 bps

Serial EEPROM $100 \mathrm{kHz}$

\section{CONCLUSION}

In this project a PIC microcontroller was used in simulation to model an access control in air traffic systems with automated on duty notification tool. This model was designed in proteus software. The model was simulated in proteus and interfaced with a GSM Module SIM 900 via USB Serial Converter to communicate with the outside world through the GSM module. This was done to create a design that can be used in the air traffic navigation industry to ensure that the air traffic service unit (ATSU) tower is always manned in order to improve safety of travel and avoid fatalities. In the scenario it is not manned the prototype will send an SMS to notify management that there is no air traffic controller (ATC) in the tower manning flights.

\section{ACKNOWLEDGEMENT}

We would like to acknowledge the Air traffic and Navigation Services Johannesburg S.A and the University of South Africa for their contribution towards this project.

\section{REFERENCE}

[1] Civil air navigation services organization (canso), “Automation Interface Between Flight Information Regions", Best Practice Guide for ANSPS, 2016.

[2] H.C Gabler, R.R. Krchnavek and J.L. Schmalzel, "Development of an automated crash notification system: an undergraduate research experience", 30th ASEE/IEEE Frontiers in Education Conference Proceedings, October 18-21, 2000, ISBN 0-7803-6424-4, DOI: 10.1109/FIE.2000.896632.

[3] W. Xiao, Z. Li, W. Chen, Y. Lu, and H. Jiang, "Trigger algorithm of vehicle automatic crash notification system", International Journal of Automotive Technology, vol. 17, no. 2, pp. 273-280, 2016, https://doi.org/10.1007/s12239-016-0027-8.

[4] C. L. Wu and R.E. Caves, "Research review of air traffic management", Transport Reviews, vol. 22, no. 1, pp. 115-132, 2002, https://doi.org/10.1080/01441640110074773.

[5] T.S Perry, "In search of the future of air traffic control", IEEE Spectrum, vol. 34, no. 8, pp. 18-35, Aug. 1997, DOI: 10.1109/6.609472.

[6] K.M. Zemrowski, "Impacts of Increasing Reliance on Automation in Air Traffic Control Systems", $2^{\text {nd }}$ Annual IEEE Systems Conference, April 2008, DOI: 10.1109 /SYSTEMS.2008.4518987.

[7] W.C Young, M. Tsai and L.M. Chuang, "Air traffic control system management", Proceedings of the IEEE 2000 National Aerospace and Electronics Conference. NAECON 2000, Engineering Tomorrow (Cat. No. 00CH37093), Oct. 2000, DOI: 10.1109/NAECON.2000.894952.

[8] O. U. Vortac, M.B. Edwards, D. K. Fuller and C.A. Manning, "Automation and cognition in air traffic control: An empirical investigation", Applied Cognitive Psychology, vol. 7, no. 7, pp. 631-651, December 1993, http://doi.org/10.1002/acp.2350070707.

[9] T. Mirchi et al, "Air Traffic Controller Trust in Automation in NextGen", Procedia Manufacturing, vol. 3, pp. 2482-2488, 2015, https://doi.org/10.1016/j.promfg.2015.07.509.

[10] F. Trapsilawati, M. K. Herliansyah, A. S. A. N. S. Nugraheni, M. P. Fatikasari and G. Tissamodie, "EEG-Based Analysis of Air Traffic Conflict: Investigating Controllers' Situation Awareness, Stress Level and Brain Activity during Conflict Resolution", The Journal of Navigation, Nov 2019, DOI: https://doi.org/10.1017/S0373463319000882.

[11] G. Di Flumeri et al, "Brain-Computer Interface-Based Adaptive Automation to Prevent Out-of-The-Loop Phenomenon in Air Traffic Controllers Dealing With Highly Automated Systems", Frontiers in Human Neuroscience, vol. 13, pp. 296, $6^{\text {th }}$ September 2019, https://doi.org/10.3389/fnhum.2019.00296. 
[12] A. Premadi, M. S. Ab-Rahman, N. B. Chuan, M. N. M. Saupe, and K. Jumari, "Application of PIC microcontroller for online monitoring and fiber fault identification", International Conference on Electrical Engineering and Informatics, vol. 2, pp. 463-467, 5-7 $7^{\text {th }}$ August, 2009, ISBN 978-1-4244-4913-2, DOI: 10.1109/ICEEI.2009.5254693

[13] C. Singh, and K. Agarwal, "Design of reactive PIC microcontroller", International Symposium on Signals, Systems and Electronics, vol. 1, pp. $1-4 . \quad 17-20^{\text {th }}$ September 2010, e-ISBN 978-1-4244-6355-8, DOI: 10.1109/ISSSE.2010.5638201

[14] F. Wu and T. He, "Application of Proteus in Microcontroller Comprehensive Design Projects", Instrumentation, Measurement, Circuits and Systems, pp. 363-369, 2012, e-ISBN 978-3-642-27334-6, https://doi.org/10.1007/978-3-642-27334-6.

[15] D. Ćika, and D. Grundler, "Proteus Virtual System Modelling used for microcontroller education", The 33rd International Convention MIPRO, pp. 1034-1038, 24-28 $8^{\text {th }}$ May 2010, e-ISBN 978-9-5323-3050-2, https://ieeexplore.ieee.org/document/5533596.

[16] Circuits Today, "Interfacing GSM module using proteus", http://www.circuitstoday.com/interfacing-gsm-module-using-proteus.

[17] Skripsi Java SMS Gateway, "Operating Mode: SMS Text Mode and SMS PDU Mode", http://skripsismsgateway.blogspot.com/2009_02_01_archive.html. 